\title{
Risk Evaluation on Security Personnel Managing Illegal Detainees in a Makeshift COVID-19 Low Risk Quarantine and Treatment Center
}

\author{
Anita Abd Rahman ( $\nabla$ anitaar@upm.edu.my ) \\ Universiti Putra Malaysia https://orcid.org/0000-0002-4228-2259 \\ Mohd Arshil Moideen \\ Ministry of Defense, Malaysia \\ Erlendawati Mohd Anuar \\ Ministry of Health, Malaysia \\ Fuad Ridha Mahabot \\ Ministry of Health, Malaysia \\ Wan Mohd Harith Wan Mustapha \\ Ministry of Health Malaysia: Kementerian Kesihatan Malaysia \\ Mohammad Farhan Rusli \\ International Islamic University Malaysia
}

\section{Research}

Keywords: HIRARC, security, illegal detainee, COVID-19

Posted Date: November 5th, 2020

DOl: https://doi.org/10.21203/rs.3.rs-89160/v2

License: (c) (i) This work is licensed under a Creative Commons Attribution 4.0 International License. Read Full License 


\section{Abstract}

Background: The COVID-19 pandemic situation in Malaysia has resulted in a whole country approach where a newly built makeshift low risk Covid-19 treatment centre was chosen to house all COVID-19 positive illegal immigrants. In view of the security situation as the risks of these detainees behaving aggressively, taking hostage, running away and escaping from the treatment centre were high, governmental, non-governmental and security agencies came together and worked alongside the healthcare personnel for this treatment centre. This paper entails risk evaluation that needs to be considered to all the security personnel working in this centre as there was no precedent of similar situation in the country.

Methodology: This is a semi-quantitative and integrated type of hazard identification, risk assessment and risk control (HIRARC) approach where it incorporates risk rating and severity rating to cover four elements, which are people, property, environment, and reputation. Total scores range from 1 to 25 and was further categorized into low, medium and high risk in a color-coded representation. The assessment was done for two weeks from $27^{\text {th }}$ May 2020 till $11^{\text {th }}$ June 2020.

Result \& Discussion: Risk evaluation identified four types of hazards which were physical, biological, psychological and ergonomics hazards. Physical hazards with possible violence and riot scored the highest risk while ergonomic issues had the lowest rating. Appropriate control measures to mitigate all the potential risks were appropriately implemented through a solid multi-agencies' collaborative effort. This evaluation serves as a good planning tool in optimizing the risk mitigation measures among security personnel working in a biological hazardous environment.

Conclusion: The mapping combination of existing hazard, risk rating and control was able to facilitate organization to prioritise future planning. With the fluidity of the COVID-19 pandemic, periodical evaluation is recommended to meet dynamic changes such as demands for frontliner manpower strength, the number of existing detainee patients in ward and the evolution of the COVID-19 infection itself in order to maintain safety and security for all. (318 words)

\section{Background}

Epidemiological data have shown that COVID-19 is a highly transmissible disease, and the risk amplifies with certain conditions such as those of older age, having co-morbid medical condition, living in closed proximity, poor hygiene and others. Among these, living in confined spaces such as detention center that caters illegal detainees is without exception as it has issues with overcrowding and personal hygiene $(1,2)$. The general procedure for managing this type of offender who is being held in custody for entering the country without a valid documentation is to send them to detention centre for legal processing and eventually deporting them back to the country of origin. During pandemic, this normal procedure is halted due to the Movement Control Order (MCO) that prohibits international travelling by most countries. This resulted in a more prolonged process of detention and deportation and therefore make them a vulnerable group as it can act as potential epicenter for COVID-19 cluster outbreak for which Malaysia has experienced it.

As one of national disaster preparedness initiative for COVID-19, a low risk quarantine and treatment centre known as PKRC (Pusat Kuarantin dan Rawatan Covid-19 Berisiko Rendah) was specifically established. With the collaborative involvement of multi-agencies, this unprecedented makeshift treatment facility took only four days to be setup. The team transformed the existing Malaysia Agro Exposition Park Serdang (MAEPS) exhibition facility into a temporary low risk quarantine and treatment healthcare facility that can cater up to 604 patients. It was built between 16th March 2020 to 20th March 2020. In the initial phase, PKRC received Malaysians and legal foreign nationality COVID-19 positive patients. To provide comfort, the setup was designed and equipped with a leisure lounge, free wireless network of $5 \mathrm{G} \mathrm{WiFi,} \mathrm{online} \mathrm{video} \mathrm{conferencing} \mathrm{support} \mathrm{for} \mathrm{mental} \mathrm{healthcare} \mathrm{and} \mathrm{gym} \mathrm{facility} \mathrm{to} \mathrm{promote} \mathrm{physical} \mathrm{activeness;} \mathrm{in}$ such a way that it resembles a homey environment to alleviate unnecessary stress of being isolated. However, on 21st May 2020, the country had a surge rise of cases from the illegal foreigners' in detention center. Because of this, the role of PKRC was changed overnight where it underwent a 180-degree transformation in terms of human resource structure and function as well as the facility itself. The changes were done within 24 hours in upscaling not only medical management but also to address the security issues in managing illegal immigrant detainees.

In public health as well as in occupational health, it is considered as an obligatory responsibility for those who create a risk to manage the risk. This can be made possible through good risk management program that can eventually developed safety culture to prevent not only injuries, but also other incidents that are costly, stressful and inconvenient. The decision for a nation strategy on containment and mitigation was decided on scientific evidence that also came enforced order of the Prevention and Control of Infectious Diseases Act 1988 and the Police Act 1967 and would help to control the spread of the virus $(3,4,5)$. This step was significant, as the situation in 
China had proved that by isolating the infected group of individuals and practicing social distancing, the pandemic was managed to be contained (6). While the infection care of the detainees remains the same as per national clinical guideline (7), one must be cautious in terms of the security and safety aspect of handling these group of people as they are with offence records that need to be dealt with according to enforcement procedures. The concern was even greater when at one period, PKRC had mass admission of over 400 detainees with COVID-19 infection. Risk from violence and aggression, possible hostage situation, self-inflict injury need to be considered as possible security related incidences. Therefore, contingency measures to respond promptly to indications of either deterioration or imminent offending where various factors had to be considered to maintain the safety and security of the facility (8). Conditions relating to human aspect both from detainee and staff perspectives had to be brainstormed such as sociodemography background, type of offences, potential risk behavior as well as job description for each personnel, number of staffing and environmental factors that could pose as potential threat. To address this systematically, risk management was done that involves the process of evaluating and minimizing the risks associated with organizational activities and systems. In many organizations the use of Hazard Identification, Risk Assessment and Risk Control (HIRARC) have become a fundamental for risk management. This is in line with Occupational Safety and Health Act 1994 under Sect. 15 that specify the general duties of employers to ensure, so far as is practicable, the safety, health, and welfare at work of all their employees (9). Therefore, this paper highlights the security related findings based on HIRARC evaluation in terms of its risk assessment and adequacy of control measures adopted for all level of personnel working in this low risk quarantine and treatment centre.

\section{Methodology}

As PKRC was a newly set up facility, one of the first task was to develop a standard operating procedure (SOP) that include a narrative explanation and a step-by-step instruction in the form of a flow chart that serve as a guide for performing the HIRARC evaluation. The purpose of establishing this SOP was to provide a process for the evaluation and management of workplace hazards and risks as well as to minimize the potential for injury, adverse health effects, or damage due to workplace incidents. Table 1 summarizes the flow of the process for PKRC.

As mentioned earlier, this was a HIRARC workplace activity to evaluate the security related hazards that can arise from managing illegal detainees who has contracted COVID-19 infection. The evaluation was done in a period of two weeks on seven enforcement and government agencies that provide security services at PKRC. It started with identifying the liaison officers of each agency and gaining access to their standard operating documents on security matters. Thereafter a walk-through inspection was done to observe on how documented operating procedure is translated into practice and whether the control measures has been implemented. This was followed by further discussion with the liaison officer in understanding the opted control measures. Finally, the evaluation was compiled and submitted for review.

\section{PEAR Model HIRARC}

In performing HIRARC evaluation, there are many methods that are available that can be adopted. The HIRARC methods used in this particular facility has incorporated the use of PEAR model that looks into four perspectives which are People, Environment, Assets and Reputation. This model is popularly used in industries such as oil and gas industries and this mnemonic PEAR is used to recall the four considerations for assessing and mitigating human factors (10). The choice to use this model was based on discussion held among four public health physicians serving at PKRC that compared few available methods and finally, consensus to use the PEAR model that was based on a qualitative score for a sound judgement were accepted as it provide comprehensive coverage to the four main elements that are of utmost importance when managing illegal detainees. When it comes to probability, a simple scale of frequency is preferred over detailed statistical formulas. Risk management information systems are helpful because they draw on historical data that increases the accuracy of probability and frequency predictions. Event that has low probability and high severity, and vice versa, should be treated with equal care. The risk matrix was based on the standard $5 \times 5$ contingency severity and risk ratings. The spectrum of total score ranged from 1 to 25 (please refer to HIRARC risk matrix in Table 2). Furthermore, the use of this matrix was also compared with regulation and it was found to be in line with the local Occupational Safety and Health Act 1994 (OSHA)-Hazard Identification, Risk Assessment and Risk Control (HIRARC), 2008 where it provides general guidelines for any industry in implementing risk assessment systems (11).

In addition, assessment was done based on the fixed zoning area of the facilities that was divided into three zones which were red, yellow and green zones as per Fig. 1. The zoning was decided based on the distance of exposure from COVID - 19 positive patient, clinical/work activity and protective infrastructure that has been in place for example, glass shielding as a separator.

Page $3 / 11$ 


\section{Result And Discussion}

Table 3 summarizes the evaluation findings based on type of hazard and its possible work activity involved where exposure from it could result in safety and security issues, assessment of the risk based on its description dan rating that uses color coding to categorize the risk as well as considering the adequacy of risk control that has been implemented.

The management for COVID-19 especially among illegal detainee has opened a different perspective that goes beyond its clinical management per se. In the case of illegal detainees, depending on who sees what and how, there is always an argument on the complex balance of security needs between human rights and appropriate health care that need to be provided to these group of population (12). One must remember that first and foremost, these detainees has an offence of having stayed in the country without legal documentation while some of them have additional violation such as criminal offences and has been convicted by the local court. As security is defined as a state where measures are taken to protect a territory, person, infrastructure, or organization, against any possible threat, this fall under the purview of the nation sovereignty in terms of legal authority on the country and its population. On that note, under the European system, it has been stated that in emergency situations, authorities may require to take measures that normally diverge from the standard human rights protection (13).

In standard practice, detainees in custody is given medical care of the same quality and standard as is available to the public. Nonetheless doctor-patient consultation should always be preceded with a safety risk assessment to ensure treatment could be given in a safe manner (14). As such this paper concentrates on presenting security related issues that were assess in managing detainee patients. The HIRARC evaluation that was used is an integrated methodology, aiming to be more transparent to cover people, property, environment, and reputation of the organization. Overall issues that were identified as posing additional risks can be broadly categorized into four (4 types) of hazards which are physical, biological, psychological and ergonomics hazards. Description details of each hazards is as below:

\section{Physical hazard}

With the ever-evolving challenge in managing pandemic situation, reports have commented that in general detention centres and its system has lack of medical access which may affect the optimum provision of good healthcare. It is especially dire for people in such facilities, given that exposure to the virus can lead to relatively quick and life-threatening consequences. As in general it may be difficult to comply with local health guidelines such as practicing frequent hand washing and physical distancing, both due to access and supplies (15). This is one of the reasons why PKRC was transformed to provide the same medical care as any human being. However, with such facility of new and unfamiliar infrastructure it could pose as potential physical hazard. This type of hazard is considered as being more relevant since risk may come from threats related to breakout/escape, riot, aggression, or self-harm from detainee. Even though data and the actual number these incidences among detainees is not readily available statistically, however it is well known to occur. One reason why healthcare facility is seen as an opportunity for escape route is the perception that security control is lax. Concurring to this reasoning was one rational why evaluation found that physical hazard gained the highest total risk rating of 25 for people, asset, and reputation. It was also the main concern for all security related agencies with the risk of bodily injury from handling potential riot, hostage or strike incidents. This situation even became a great concern as the number of inpatient detainees reached up to 400 at one time.

The countermeasure adopted uses the concept Defence in Depth (DiD) where a series of defencive mechanism are layered to protect what should be protected and in the case of PKRC, it is the people and asset. When implemented correctly and maintained properly, defence in depth leads to a reasonable level of security. Therefore, mitigation that was put in place by collaboration with various agencies included a four-level security which are:

- First level - This is implemented in the red and yellow zones where immigration officers has the authority to guard this group of people through the function of a special tactical team that act to contain immediate unwanted incident and to bring other staff out to safety.

- Second level- This is in the form of a 24-hour standby police team as well as the use of approximately $2 \mathrm{~km}$ length of concertina wire that surrounds the facility in enhancing reinforcement to the first line defence mechanism.

- Third level - Approximately 13 allotted control posts guarded by a combined team of police, military and RELA (People Volunteer Corp) that goes on watch $24 / 7$ located outside the concertina perimeter. 
- Fourth level - The last defense was in the form of regular on wheel patrol by both the police and security officers of the Agro park itself.

In addition to having multilayer security level, other mitigation included was having repeated number of practical simulations for riot scenario as well as having ongoing medical related dry run that could lead to potential unwanted incident to occur. This simulation exercise was done at different shift and place to reflect the possibility of any unwanted event that can occur anytime and anywhere within the facility. This was also done to strengthen the command, control, and coordination among multiagency.

\section{Biological hazard}

With the ever evolving in the pandemic situation, reports have commented that in general detention centres and its system has lack of medical access which may affect the optimum provision of good healthcare. It is especially dire for people in such facilities, given that exposure to the virus can lead to relatively quick and life-threatening consequences as well the difficulty in complying to the local health guidelines $(2,15)$.

As such, the government has decided that these infected detainees received medical care at this low risk quarantine and treatment centre or commonly known as PKRC. Based on the whole operation, more than half (59.6\%) of COVID-19 positive detainees had a clinical staging of category 1 and 2 which are asymptomatic and symptomatic with no pneumonia (16). The assessment was done based on zoning area of the facilities that was divided into three zones; i.e red, yellow and green zones as per Fig. 1. The zoning was decided based on the distance of exposure from COVID - 19 positive patient, clinical/work activity and protective infrastructure that has been in place for example, glass shielding as a separator. For medical care, each cubicle ward (4 metre width, 12 metre length) houses 4 to a maximum of 6 patients with ample space clearance as well as necessities being provided for personal care and hygiene. The whole area has in total 36 cubicles with a total bed capacity for 216 patients. As part of preparedness should there be a surge of cases, the area can house up to another 34 beds to full maximum capacity of 250 beds This subsequently translate to the type of personal protective equipment that is needed to be worn when working in each zone.

Based on rating, the highest score was found to be 20 and as such, those working in the red zone that deals directly with detainee and has higher risk and were mandated to wear full PPE which include Tyvek suit, N95 mask with face shield, plastic apron, shoe cover and double gloving as part of minimizing the risk. However, PPE has its own risk if not properly worn especially during doffing post shift. Therefore, the role of the infection control team in monitoring PPE procedure such as proper donning and doffing techniques was assessed periodically and on spot check basis. At the same time, PKRC also embarked on a health surveillance monitoring where those frontliners irrespective of agencies were randomly chosen to undergo nasopharyngeal/oropharyngeal swab testing for COVID-19 to assess for possible workplace exposure. Approximately 520 of them (representing nearly $50 \%$ of total staffing) were swabbed and all results reported were negative.

From another positive angle, while maintaining the right to non-discrimination and equality in access to healthcare and health services, this evaluation was also one approach to portray that the collaborative arrangement between agencies facilitate better preparedness in terms of managing security related issues so as not to disrupt health-care delivery within centre that cater this vulnerable group (17). Other danger that may arise was from the environment factor such as the existence of wildlife animals. This is not surprising as the surrounding area is an agritourism park resides on a 130 hectares of land belonging to the Malaysian Agricultural Research and Development Institute (MARDI). There was one incident reported where a frontliner while on his round duty, found a phyton in a manhole. This was probably due to weather condition where at that time, it was a dry and hot season where animal tend to seek hiding in confined spaces to reduce heat exposure. This was rectified by sealing all possible manhole. Thereafter, no incident was reported. Lesson learned from such pandemic is that it gives all security-related agencies to develop and/or strengthened their standard operating procedures in managing detainees with illness and in future become more prepared to handle such similar incidents.

\section{Psychological hazard}

As this is a novel pandemic, the management of patient without a doubt created a lot of anxiety, fear, and stress. This was related to the amount of workload, issues related to the new norm working environment such as having to use full PPE most of the time. In addition, as PKRC is unique in the sense that it caters for illegal detainees, other psychological issues that arose were the feeling of boredom due to certain monotonous activity such as guarding at the control post. The variety of the psychological spectrum was influenced by the role of different agency and the different work zone area where higher score was found from those working in the red zone with a score of 20 while working in the green zone such as guarding at control post has lower scoring 6 for rating score. 
A cross-sectional comparative study that examined psychological distress, depression, anxiety, and stress experienced by 470 health care workers in Singapore during the COVID-19 outbreak between medically and non-medically trained hospital personnel (clerical staff, administrator and maintenance workers found that there were $68(14.5 \%)$ participants screened had anxiety, while depression and stress were $42(8.9 \%)$ respectively. The prevalence of the psychological impact was lower than those in the published literature from previous disease outbreaks and this could be due past Severe Acute Respiratory Syndrome (SARS) experience that improved mental preparedness and enhanced a more definitive infection control measure (18). With this known knowledge, PKRC set up a special unit to cater the mental health psychospiritual support (MHPSS) to all staff in need. The strength of people that operates this unit include psychiatrist, psychologist, counsellor, and religious expert from Ministry of Health and The Military Religious Corps. As part of formal services, pre deployment briefing and post deployment debriefing was given to all staff who worked at PKRC.

On the perspective of the detained patients a study postulated that the coronavirus pandemic could adversely affect the mental health of prisoners and further increase rates of self-harm, and the negative psychological effects of quarantine (19). Form patient's perspective, this service was also provided but with more controlled environment. However, during the facility entire operation, there were no major violence occurred and care was given in a peaceful manner. This may be consistent with the finding that although numerous negative psychological consequences are associated with confinement and social isolation, spending time in this makeshift facility has probably reduced prisoners' exposure to negative and intimidating behaviours, such as bullying, threats and violence from other inmates. This was even considered as a privilege of having a conducive therapeutic environment, thus increasing their overall sense of safety and security (20).

\section{Ergonomics hazard}

One of the daily activities that has potential to cause health ill effect was related to food distribution and serving to patients due to its regular repetitive motion in order to distribute 3 times meal a day to 400 existing detainees' patients in a period of 45 minutes for each meal session. This activity must be completed by 5 staff per shift where 2 persons works in the yellow zone while the remaining 3 works in the red zone. At the same time due to security issues related to illegal detainees, this job scope had to be modified with the use of artificial intelligence. Through observation, packed foods were brought into different zone in ward using different method where from the green to yellow zone until the entrance of red zone, food was transferred using manual procedure with the aid of trolley. Thereafter from red zone, food was distributed directly to patients using robotic equipment thus minimizing repetitive motion. This modification also eliminates manual handling and renders the category of risk as low with a rating score of only 4 . At the same time, the use of this locally developed robotic technologies in distributing the foods have help mitigate the risk of infection due to proximity.

Based on the whole assessment, an infographic in Fig. 2 was drawn to represent the combination of the overall HIRARC findings. The infographic not only depict in terms of risk level but also be explained in terms of the extend of risk based on width of area. Another way to make the infographic better is to use the common color coding of risk where red represent high risk, yellow as medium risk and green colour as low risk. It was found that physical hazard has all three-risk level with high risk representing the biggest perimeter area as possibility to physical injury from security issues in managing illegal detainees remains a constant priority issue. This was the reason for the multilevel DiD was put in place. Vice versa, risk from exposure of COVID-19 patients as biological hazard was given as low risk with the widest perimeter area as the prevention and control measures that has been adopted was able to minimize the risk of cross infection. There was still possibility of high and medium risks especially in the red sone working area but with good control measures such as the use of PPE, distancing practice was able to bring down the risk to level lower. Similarly, ergonomic hazard was also given low risk with the use of artificial intelligence that eliminated manual handling and repetitive motion. Generally, with the current assumed prevention and control methods used has facilitated the government and public health practitioners in tackling safety and security issues among all staff as well as managing morbidity among these marginal group. At the same time, involvement through multiagencies approach remains relevant as it lessens the work burden and does not overwhelms the overall healthcare services (21). Even though the semi-quantitative risk rating was done during a period that had certain preparedness level, risk remain an uncertain which may need to be assessed in terms of frontliner man power strength, the number of existing detainee patients in ward and the evolution of the COVID-19 infection. In summary, this type of infographic presentation will not only facilitate organization to visualize the combination of existing hazard, its risk level as well as a check and balance approach for assessing the prevention and control measures in place, it also can be used for mapping out and comparing the dynamic in changes of the risk through snapshot of times.

\section{Conclusion}

This novel COVID-19 pandemic continues to create uncertain situation in terms of its magnitude, its speed of spreads and the heterogeneity of people being infected. There is a need for a continuous counterbalance between the protection in terms of security of 
the detainee in custody, with the need to protect their health within the use of healthcare services for necessary cases. This integrated HIRARC methodology serve as a concrete and relevant tool in assessing security related issue when managing COVID positive detainees that show the government effort in providing access and available necessary health care with equality.

\section{Abbreviations}

COVID-19

Coronavirus Disease 2019; PKRC:Pusat Kuarantin dan Rawatan Covid-19 Berisiko Rendah; HIRARC:Hazard Identification risk Assessment and Risk Control; PEAR:People, Environment, Asset, Reputation; SOP:Standard Operating Procedure; DiD:Defence in Depth; OSHA:Occupational Safety and Health Act 1994; MHPSS:Mental Health Psycho-Spiritual Support; PFA:Psychological First Aids; RELA:People Volunteer Corp; PPE:Personal Protective Equipment.

\section{Declarations}

This is to declare that this manuscript is original, has not been published before and is not currently being considered for publication elsewhere.

\section{Acknowledgement}

Appreciation goes to the Director of the COVID-19 Low Risk Quarantine and Treatment Center (PKRC) Dr Md Anuar Abd Samad @ Mahmood for the support on this assessment to be done for the facility with heartfelt gratitude to all PKRC frontliners for the undying commitment, hard work and bravery in protecting our nation against this pandemic.

\section{Ethical Approval}

Not applicable as the manuscript findings does not report on human data.

\section{Consent for Publication}

Not applicable.

\section{Availability of Data and Materials}

All data generated or analysed during this study are included in this published article as per explained in methodology.

\section{Competing Interest}

The authors declare no conflict of interest.

\section{Funding}

The research received no external funding.

\section{Authors Contribution}

AAR and MAM designed the research. EMA, WMHWM and FRM validated the methodology. All authors participated in data collection. AAR drafted the manuscript. All authors read and approved the final manuscript.

\section{References}

1. Caputo F, Gratteri S, Sacco MA, Scalise C, Cacciatore G, Bonetta F, Zibetti A, De Aloe L, Sicilia F, Cordasco F, Ricci P, Aquila I. Covid-19 emergency in prison: Current management and forensic perspectives. Medico-Legal Journal. 2020;1-2. Available from: https://doi.org/10.1177/0025817220923693.

2. Miller HV, Ripepi M, Ernstes AM, Peguero AA. Immigration Policy and Justice in the Era of COVID-19. Am J Crim Just. 2020;45:793809 Available from: https://doi.org/10.1007/s12103-020-09544-2.

3. Bernama. Health DG. Movement Control can boost Misitry's fight against Covid-19. The Star. 2020. Available from: https://www.thestar.com.my/news/nation/2020/03/17/health-dg-movement-control-can-boost-ministry039s-fight-against-covid-19 
(accessed May 18, 2020).

4. Laws of Malaysia. Prevention and Control of Infectious Diseases Act. 1988.

5. Laws of Malaysia. Polis Act. 1967. Available from: http://www.agc.gov.my/agcportal/uploads/files/Publications/LOM/EN/Act\%20344\%20-\%20Police\%20Act\%201967.pdf (accessed May 20, 2020).

6. World Health Organisation (WHO). Coronavirus disease 2019 (COVID-19) situation report-44. 2020. Available from: https://www.who.int/docs/default-source/coronaviruse/situation-reports/20200304-sitrep-44-covid-19.pdf?sfvrsn=783b4c9d_2 (accessed May 25, 2020).

7. Ministry of Health (MOH). Guidelines COVID-19 Management in Malaysia No.5/2020. 2020. Available from: http://covid19.moh.gov.my/garis-panduan/garis-panduan-kkm (accessed June 30, 2020).

8. United Nations Office on Drugs and Crime (UNODC). Handbook on the Management of High-Risk Prisoners. 2016. UN Office. Vienna. Available from: https://www.unodc.org/documents/justice-and-prison-reform/HB_on_High_Risk_Prisoners_Ebook_appr.pdf (accessed August 26, 2020).

9. Department of Safety of Health Malaysia. Occupational Safety and Health Act. Putrajaya: Ministry of Human Resources, Federal Government Administrative Centre; 1994.

10. Aven T, Vinnem JE, Wiencke HS. A decision framework for Risk assessment, with application to the offshore oil and gas industry. Reliability Engineering System Safety. 2007;92:15-24.

11. Department of Safety of Health Malaysia (DOSH). Guidelines for Hazard Identification, Risk Assessment and Risk Control (HIRARC). 2008. Ministry of Human Resources, Federal Government Administrative Centre, Putrajaya. Available from:

https://www.dosh.gov.my/index.php/legislation/guidelines/hirarc-2/1846-01-guidelines-for-hazard-identification-risk-assessmentand-risk-control-hirarc-2008/file (accessed on June 30, 2020).

12. Tozzo P, Gabriella D'Angiolella G, Caenazzo L. Prisoners in a pandemic: We should think about detainees during Covid-19 outbreak. Forensic Science International: Synergy. 2020;2:162-3.

13. European Convention on Human Rights: Article 15. 2013. European Court of Human Rights Council of Europe F-67075 Strasbourg. Available from: https://www.echr.coe.int/Documents/Convention_ENG.pdf (accessed on July 13, 2020.

14. Ministry of Health, Malaysia (MOH). Guidelines on Management of Detainees in Custody Presented to the Emergency and Trauma Department. 2018. Emergency Services Unit, Medical Development Division. Available from: https://www.moh.gov.my/moh/resources/Penerbitan/Garis\%20Panduan/Garis\%20Panduan\%20Umum(KKM)/ 20180312_GUIDELINES_ON_MANAGEMENT_OF_PATIENTS_IN_POLICE_CUSTODY.pdf. (accessed July 7, 2020).

15. National Centre for Immunization and Respiratory Disease (NCIRD), Division of Viral Diseases. Interim Guidance on Management of Coronavirus Disease 2019 (COVID-19) in Correctional and Detention Facilities. 2020. Available from: https://www.cdc.gov/coronavirus/2019-ncov/community/correction-detention/guidance-correctional-detention.html (accessed August 18, 2020).

16. Ministry of Health, Malaysia (MOH). Clinical Management of Confirmed Case. Annex 2e. 2020. Available from: https://www.moh.gov.my/moh/resources/Penerbitan/Garis\%20Panduan/COVID19/Annex_2e_Clinical_Management_22032020.pdf (accessed July 29, 2020).

17. World Health Organisation (WHO) Preparedness, prevention and control of COVID-19 in prisons and other places of detention. 2020. World Health Organization Regional Office for Europe. Copenhagen, Denmark.

https://www.euro.who.int/_data/assets/pdf_file/0019/434026/Preparedness-prevention-and-control-of-COVID-19-in-prisons.pdf. (accessed May 25, 2020).

18. Tan BYQ, Chew NWS, Jin M, Goh Y, Teo LLL, Zhang K, Chin HK, Ahmad A, Khan FA, Shanmugam GN, Chan BPL, Sunny S, Chandra B, Ong JJY, Paliwal PR, Wong LYH, Sagayanathan R, Chen JT, Ying Ng AY, Teoh HL, Ho CS, Ho RC, Sharman VK. Psychological Impact of the COVID-19 Pandemic on Health Care Workers in Singapore. Ann Intern Med. 2020;M20-1083. Available from: doi: 10.7326/M20-1083.

19. Brooks SK, Webster RK, Smith L, Woodland L, Wessley S, Greenberg N. The psychological impact of quarantine and how to reduce it: rapid review of the evidence. Lancet. 2020;395(10227):912-20.

20. Hewson T, Green R, Shepherd A, Hard J, Shaw J. The effects of COVID-19 on self-harm in UK prisons. BJPsych Bulletin. 2020;1-3. Available from: doi: https://doi.org/10.1192/bjb.2020.83. 
21. Anderson RM, Heesterbeek H, Klinkenberg D, Hollingsworth TD. How will country-based mitigation measures influence the course of the COVID-19 epidemic? Lancet. 2020;395:931-4.

\section{Tables}

Due to technical limitations, table 1 is only available as a download in the Supplemental Files section.

Table 2

Risk Matrix for Hazard Identification, Risk Assessment and Risk Control (HIRARC) Evaluation based on PEAR Model

\begin{tabular}{|c|c|c|c|c|c|c|c|c|c|}
\hline \multicolumn{5}{|c|}{ Consequences } & \multicolumn{5}{|c|}{ Risk Rating } \\
\hline \multirow{2}{*}{$\begin{array}{l}\text { Severity } \\
\text { rating }\end{array}$} & $\mathbf{P}$ & E & A & $\mathbf{R}$ & 1 & 2 & 3 & 4 & 5 \\
\hline & People & Environment & Asset & Reputation & $\begin{array}{l}\text { Very } \\
\text { unlikely } \\
(0- \\
20 \%)\end{array}$ & $\begin{array}{l}\text { Likely } \\
(20- \\
40 \%)\end{array}$ & $\begin{array}{l}\text { Possible } \\
(40- \\
60 \%)\end{array}$ & $\begin{array}{l}\text { Probable } \\
(60- \\
80 \%)\end{array}$ & $\begin{array}{l}\text { Highly } \\
\text { Likely } \\
(80- \\
100 \%)\end{array}$ \\
\hline 1 & $\begin{array}{l}\text { Negligible/ No } \\
\text { injury }\end{array}$ & $\begin{array}{l}\text { No/slight } \\
\text { effect }\end{array}$ & $\begin{array}{l}\text { No/slight } \\
\text { damage }\end{array}$ & $\begin{array}{l}\text { No/slight } \\
\text { impact }\end{array}$ & 1 & 2 & 3 & 4 & 5 \\
\hline 2 & Minor/ First aid & Minor effect & $\begin{array}{l}\text { Minor } \\
\text { damage }\end{array}$ & Minor impact & 2 & 4 & 6 & 8 & 10 \\
\hline 3 & $\begin{array}{l}\text { Moderate/ } \\
\text { Medical } \\
\text { management }\end{array}$ & Local effect & $\begin{array}{l}\text { Local } \\
\text { damage }\end{array}$ & $\begin{array}{l}\text { Considerable } \\
\text { impact }\end{array}$ & 3 & 6 & 9 & 12 & 15 \\
\hline 4 & Single fatality & Major effect & $\begin{array}{l}\text { Major } \\
\text { damage }\end{array}$ & $\begin{array}{l}\text { Major } \\
\text { national } \\
\text { impact }\end{array}$ & 4 & 8 & 12 & 16 & 20 \\
\hline 5 & Multiple fatality & $\begin{array}{l}\text { Extensive } \\
\text { effect }\end{array}$ & $\begin{array}{l}\text { Extensive } \\
\text { damage }\end{array}$ & $\begin{array}{l}\text { Major } \\
\text { international } \\
\text { impact }\end{array}$ & 5 & 10 & 15 & 20 & 25 \\
\hline
\end{tabular}

1-6 TOLERABLE- may be acceptable but review task to see if risk can be reduced further.

(LOW RISK)

8-12 COMPULSORY IMPACT REDUCTION - task should be undertaken with planned approach to control risks and

(MODERATE

RISK)

$15-25$

(HIGH RISK)

applies temporary measures if required

INTOLERABLE- task must not proceed and IMMEDIATE actions with further control measures put in place to reduce risk control.

Due to technical limitations, table 3 is only available as a download in the Supplemental Files section.

\section{Figures}


EXAMPLE OF A

CUBLICLE WITH 6 BEDS

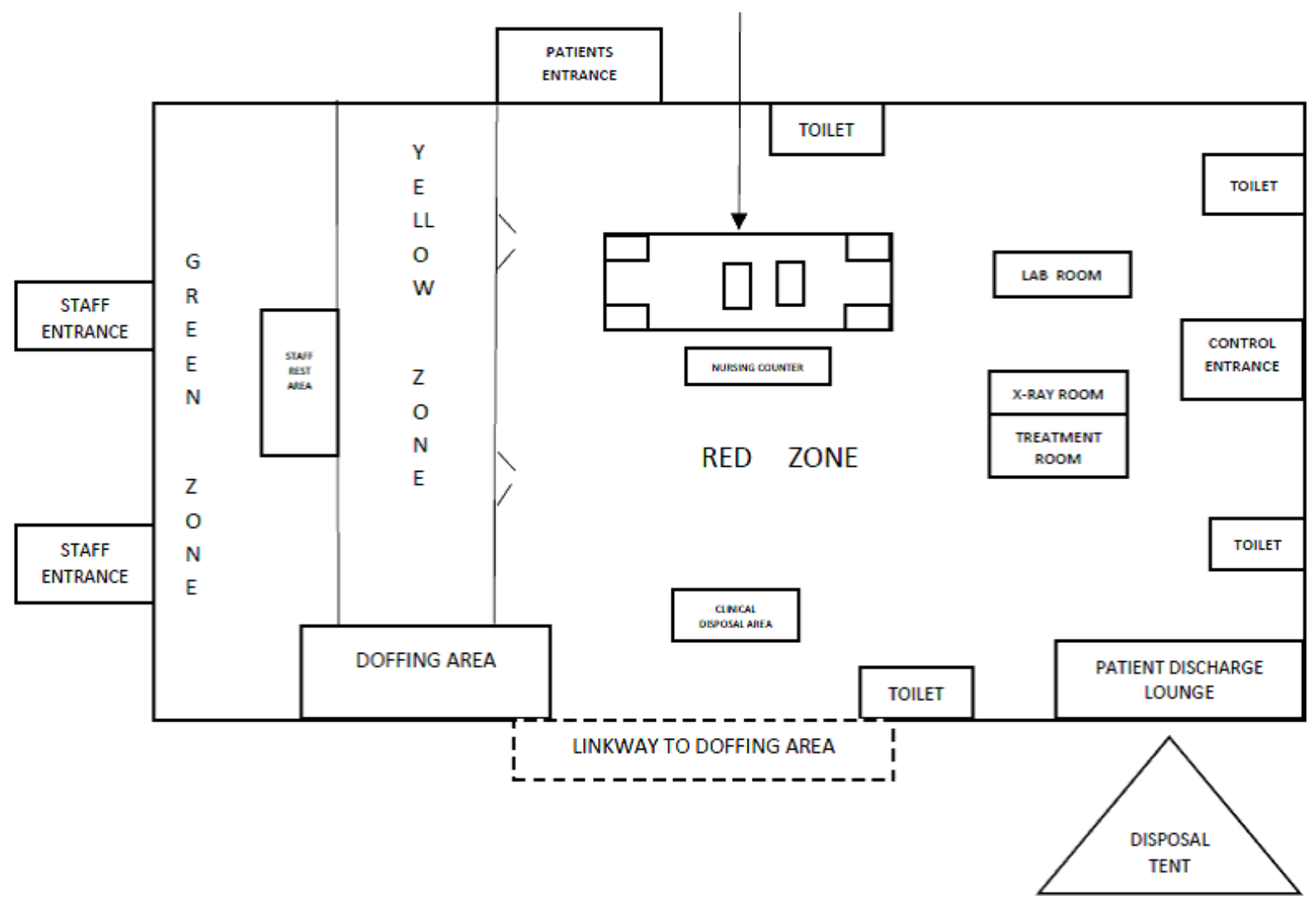

Figure 1

PKRC zoning area in a hall that was converted into COVID-19 ward that was built based on distances of at least 3 meters apart, separated by a plastic/wood pallet partition in order to provide safe work practices as well security measures when handling COVID-19 patients. It was then demarcated according to three zones which were red, yellow, and green zones. 
PHYSICAL HAZARD

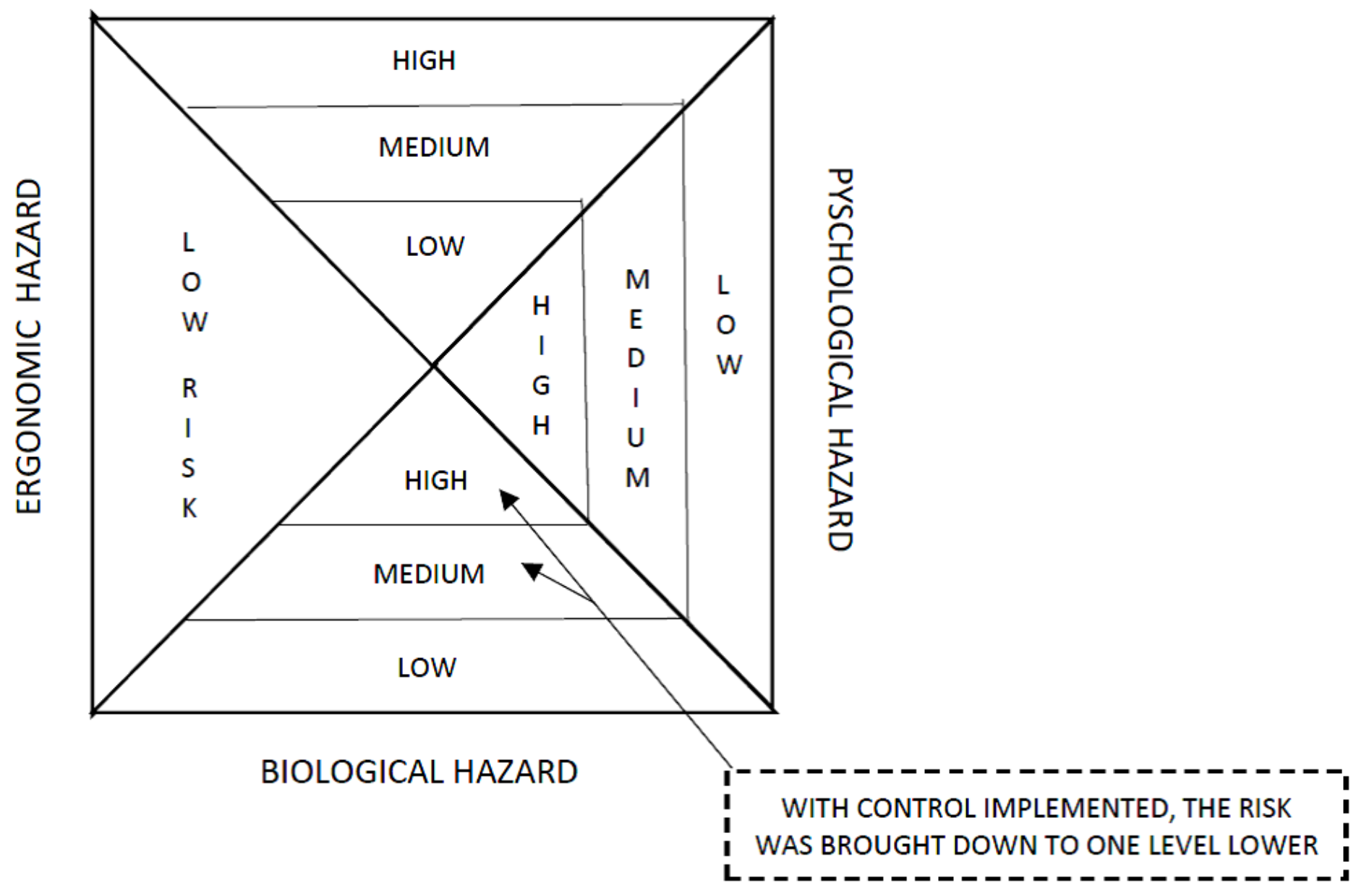

Figure 2

Infographic illustration on the overall risk matrices on security assessment at the PKRC facility that provide the overall HIRARC evaluation. Physical hazard from security issues of managing illegal detainee remains as high risk which need constant assessment of the control measures in place.

\section{Supplementary Files}

This is a list of supplementary files associated with this preprint. Click to download.

- Table1.JPG

- Table3.JPG 